\title{
A Relação Família-Escola e a Prática do "Dever de Casa" de Matemática: um estudo sobre seus tensionamentos
}

\author{
The Family-School Relationship and the Mathematics Homework: a study \\ about their tensions
}

\author{
Gelsa Knijnik $^{* *}$ \\ Débora de Lima Velho Junges ${ }^{* * *}$
}

\begin{abstract}
Resumo
O trabalho tem por objetivo problematizar os tensionamentos produzidos na relação família-escola mediante a prática do "dever de casa" de Matemática. Seu referencial teórico é a Perspectiva Etnomatemática concebida na interlocução com as formulações de Foucault e as de Wittgenstein que correspondem ao período de maturidade de sua obra. O lócus do estudo foi a (única) escola multisseriada de Morro dos Bois (município de Novo Hamburgo RS) e entrevistas foram utilizadas como procedimento metodológico. Os resultados do estudo mostram que o "dever de casa" (de Matemática): a) mobiliza os alunos e suas mães que, assujeitadas pelos discursos que circulam na sociedade, sentem-se impelidas a prestar-lhes ajuda; essa ajuda opera de modo estratégico no controle, por parte da família, daquilo que é realizado na escola; e b) a prática do “dever de casa" de Matemática está marcada por tensionamentos produzidos pelo uso (da escola e dos familiares) de jogos de linguagem diferentes (apesar de suas semelhanças de família).
\end{abstract}

Palavras-chave: Educação Matemática. Relação Família-Escola. “Dever de Casa” de Matemática.

\begin{abstract}
This paper aims to problematize the tensions produced by the family-school relationship and the practice of mathematics homework. Its theoretical framework is a Ethnomathematics Perspective conceived by the interlocution

\footnotetext{
* Este texto é uma versão modificada do trabalho "Educação matemática e relação família-escola: um estudo no âmbito do 'dever de casa", apresentado na 36ª Reunião Nacional da Anped (Campus Samambaia/UFG - 29/09 a 02/10/2013).

** Doutora em Educação pela Universidade Federal do Rio Grande do Sul (UFRGS). Professora do Programa de PósGraduação em Educação da Universidade do Vale do Rio dos Sinos (UNISINOS), São Leopoldo, RS, Brasil. Endereço para correspondência: Rua Mariante, 322/502, CEP: 90430-180, Porto Alegre, RS, Brasil. E-mail: gelsak@unisinos.br.

* Doutoranda e Mestre em Educação pela Universidade do Vale do Rio dos Sinos (UNISINOS), São Leopoldo, RS, Brasil. Endereço para correspondência: Av. Imperatriz Leopoldina, no 2500, apto 131, Bairro Pinheiros, CEP: $93042-$ 030, São Leopoldo, RS, Brasil.E-mail: deborajunges@gmail.com.
} 
with the Foucault's notions and Wittgenstein's ideas that correspond to his later work. The locus of the study was (the unique) multigrade school of Morro dos Bois (Novo Hamburgo municipality - RS). Its data are composed by interviews. The analytic exercise shows that de mathematics homework: a) mobilize students and their mothers who, subjected by the discourses that circulate in society, feel committed to help them; this help operates as a family control strategy about what is done at school; and c) the homework practice is marked by tensions produced through school and family's use of different mathematical language games (besides their family reseamblances).

Keywords: Mathematics Education. Family-school Relationship. Mathematics Homework.

\section{Introdução}

Este artigo propõe uma discussão pertinente ao currículo escolar, especificamente no âmbito da Educação Matemática. Tem o intuito de problematizar a relação família-escola desde a perspectiva dessa área do conhecimento, considerando a intensificação dessa relação que tem ocorrido nas últimas décadas, muito em função de políticas públicas implementadas no país. Exemplos dessas políticas são a $\mathrm{LDBEN}^{1}$, o Estatuto da Criança e do Adolescente ${ }^{2}$ e o PNE 2011/2020 ${ }^{3}$, que evidenciam o propósito do Estado de que a educação seja assumida como responsabilidade de todos, estimulando a participação das famílias nos processos de aprendizagem escolar. O compartilhamento de responsabilidades no contexto educacional brasileiro, nas duas últimas décadas, tem sido compreendido por pesquisadores como Dal'Igna (2011), implicado em uma mudança de significação da relação família-escola, na contemporaneidade, na qual família e escola passam a ser compulsoriamente parceiras no gerenciamento dos riscos do desempenho escolar. Para a autora, uma das consequências produzidas por essa parceria seria o "borramento de fronteiras", no qual a família é convidada pela escola a frequentar seu espaço, a participar de atividades e a tomar decisões. Outra decorrência seria o "alargamento de funções", uma vez que a tarefa de ensinar passa a ser também uma atribuição da família. Esses dois processos ganham maior intensidade na medida em que políticas públicas e ações delas decorrentes circulam na mídia, reforçando as

\footnotetext{
${ }^{1}$ A LDBEN - Lei de Diretrizes e Bases da Educação Nacional, de 1996, prevê a participação das famílias no processo de ensino e de aprendizagem de forma interligada com a escola, como referenciado no artigo 12, inciso VI, no qual pontua que os estabelecimentos de ensino têm a incumbência de "articular-se com as famílias e a comunidade, criando processos de integração da sociedade com a escola".

${ }^{2}$ O ECA - Estatuto da Criança e do Adolescente, de 1990, assegura o direito dos pais ou responsáveis de participar da definição das propostas educacionais e ter ciência do processo pedagógico como uma estratégia de interlocução entre família e escola (artigo 53, inciso V, parágrafo único).

${ }^{3}$ Uma das estratégias previstas pelo Plano Nacional de Educação para o decênio 2011-2020 é mobilizar as famílias com o propósito de que a educação seja assumida como responsabilidade de todos, articulando a educação formal com experiências de educação popular e cidadã (BRASIL, 2012).
} 
responsabilidades da família no que tem sido nomeado, no campo educacional, por "sucesso escolar" 4 .

Uma revisão da literatura dos últimos quinze anos indica a existência de um volume expressivo de publicações que discutem a temática relação família-escola no Brasil, enfocando-a sob diferentes prismas. Pesquisadores como Carvalho (2000) e Oliveira e Marinho-Araújo (2010) evidenciam que é recorrente a culpabilização das famílias pelo não sucesso escolar, em decorrência da falta de envolvimento familiar no processo educacional. Nessa direção encontramse os estudos de Reali e Tancredi (2005) e Chechia e Andrade (2005), que apontam a parceria da família como condição necessária para o sucesso no processo de ensino-aprendizagem. Esses trabalhos consideram os deveres de casa como uma das principais estratégias de formalização da relação família-escola.

A prescrição de deveres de casa tem sido utilizada pelos professores como forma de aproximação das famílias com o contexto escolar e um dos recursos que permite à família acesso aos conteúdos estudados pelos alunos (CARVALHO, 2000, 2004 e 2006). Além disso, pesquisas como as de Chechia e Andrade (2002, 2005) observaram que pais de alunos com sucesso escolar auxiliam os filhos nos deveres de casa, em especial as mães, que se mostram mais presentes no acompanhamento das tarefas. As autoras identificam a existência de tensões que permeiam a participação das famílias nos deveres de casa, uma vez que essas sentem dificuldades em auxiliar seus filhos, por não terem se apropriado dos conteúdos trabalhados pela escola, em razão de seu próprio nível de escolarização.

A revisão de literatura indicou que, apesar de o dever de casa ter sido referenciado como estratégia de participação das famílias na escola, e estudos sobre o tema terem sido desenvolvidos em anos recentes, as publicações brasileiras (como as acima mencionadas) não tratam especificamente dos deveres de casa na área da Matemática. É somente em âmbito internacional que se encontram pesquisas que examinam essa especificidade, tendo como principal referência

\footnotetext{
${ }^{4}$ De acordo com Glória (2005, p. 32), a definição de "sucesso escolar" apresentou alterações ao longo das publicações no campo da educação. Para a autora, atualmente, "o sucesso escolar é compreendido por um itinerário que se faz sem rupturas e que se prolonga até a universidade, o que tende a refletir um bom desempenho na escola". Portanto, o "sucesso escolar" estaria relacionado à não ocorrência de distorção idade-ano, ou seja, à não defasagem entre a idade do aluno e o ano que deveria estar cursando (a idade para ingresso é a partir dos seis anos, conforme alterações na LDBEN de 1996, mediante a Lei Federal $n^{\circ} 11.274 / 2006$ ), e à não interrupção do processo sequencial de escolarização, gerada pela repetência e/ou pela evasão escolar.
} 
os estudos de Guida de Abreu e de seu Grupo de Pesquisa da Universidade de Oxford Brookes (tais como as de Abreu e Cline (2005) e por McMullen e Abreu (2009)).

Os estudos realizados na universidade inglesa têm como foco a aprendizagem da Matemática, buscando compreender o impacto das culturas de casa nessa aprendizagem. $\mathrm{O}$ impacto é examinado com ênfase nos procedimentos pedagógicos e nas ferramentas utilizadas pelos professores, tais como o uso de jogos e de calculadora e realização das quatro operações. $\mathrm{O}$ programa investigativo, situado no campo da Psicologia Cognitiva, tem dado importantes contribuições para as discussões sobre o tema do dever de casa de Matemática.

É nesse contexto que foi concebida a pesquisa que embasa o presente artigo. Com o intuito de problematizar a relação família-escola, enfocando o olhar sobre o currículo escolar no âmbito da Matemática, buscou-se contribuir para as reflexões que já vem sendo realizadas. Tal contribuição pode também ser pensada no que diz respeito ao enfoque teórico dado a este estudo, uma vez que, no Brasil, existem poucas investigações sobre o currículo escolar que atentem para as dimensões culturais, sociais e políticas a ele pertinentes. Constata-se que há um significativo número de pesquisas que abordam a dimensão normativa do currículo, com enfoque em questões relativas aos conteúdos, às estratégias metodológicas de ensino e de aprendizagem e à avaliação (Silva e Pires (2013), Moreira (2012), Aguiar e Ortigão (2012)).

Neste artigo, examina-se a relação família-escola no âmbito do "dever de casa" de Matemática, a partir do referencial teórico nomeado por Knijnik (2012) de Perspectiva Etnomatemática, concebida na interlocução com as formulações de Michel Foucault e as ideias de Wittgenstein discutidas pelo filósofo a partir de sua obra "Investigações Filosóficas" (1999). Essa interlocução, discutida em maior profundidade na próxima seção, possibilitou que fossem investigados jogos de linguagem matemáticos praticados pelas famílias e aqueles praticados na forma de vida escolar, apontando para suas semelhanças e especificidades.

$\mathrm{O}$ artigo é fruto de uma pesquisa que integra um projeto mais amplo ${ }^{5}$, que examinou a relação entre a (única) escola multisseriada do campo da localidade de Morro dos Bois, situada na região de colonização alemã do Vale do Rio dos Sinos (RS), e sete famílias cujos filhos ali estudavam. Essa localidade, assim como o município ao qual pertence, foi colonizada a partir de

\footnotetext{
${ }^{5} \mathrm{O}$ referido projeto, apoiado pelo CNPq e FAPERGS, ainda em curso, é composto por três subprojetos. Um desses subprojetos tem como foco a discussão, sob diferentes aspectos, de escolas multisseriadas do campo da região de colonização alemã do Vale do Rio dos Sinos e do Vale do Taquari, situadas no Estado do Rio Grande do Sul.
} 
1824, com a chegada dos primeiros imigrantes alemães. Estudos sobre a imigração alemã no Rio Grande do Sul têm mostrado que a valorização da instituição escolar foi, desde o início, uma das marcas desse processo imigratório (KREUTZ, 2001; DREHER, 2008). Quando da realização do trabalho de campo, pode-se perceber que, em Morro dos Bois, nos dias de hoje, tal valorização segue presente ${ }^{6}$.

\section{Referencial teórico}

Esta seção tem o intuito de apresentar, mesmo que de modo sintético, o referencial teórico do estudo ${ }^{7}$. Como antes indicado, esse referencial consiste na Perspectiva Etnomatemática concebida como uma caixa de ferramentas ${ }^{8}$ que "permite analisar os jogos de linguagem matemáticos de diferentes formas de vida e suas semelhanças de família, bem como os discursos eurocêntricos da matemática acadêmica e escolar e seus efeitos de verdade” (KNIJNIK, 2012, p. 90). O uso, no campo da Educação Matemática, de noções advindas de duas perspectivas pertencentes a tradições filosóficas tão distintas é justificado devido às posições não essencialistas e não metafísicas dos dois filósofos, os quais refutam a crença da existência dos objetos em si mesmos, independentemente do contexto em que existam; o significado convergente que Wittgenstein e Foucault atribuem à linguagem, concebendo-a como imbricada a seu uso na prática comunicativa; e a proximidade teórica da noção wittgensteiniana de jogos de linguagem e a noção foucaultiana de práticas discursivas, uma vez que os discursos são

\footnotetext{
${ }^{6}$ A análise do material empírico produzido no trabalho de campo na escola de Morro dos Bois, tais como documentos da escola e ata de reuniões, assim como a realização de observações de aula e de reuniões de pais, e de entrevistas com as famílias e com a professora da escola, nos levou a essa afirmação, que é convergente com os estudos sobre a imigração alemã e a valorização da escolarização, desenvolvidos por Bredemeier (2010). No entanto, por limitações de espaço, uma discussão sobre este ponto não é aqui realizada.

${ }^{7}$ Foge ao escopo deste artigo uma discussão aprofundada das noções de Foucault (como a de discurso, enunciado, jogos de poder e "verdade") e as de Wittgenstein (como as de jogos de linguagem, uso e formas de vida) utilizadas na formulação da Perspectiva Etnomatemática aqui apresentada, assim como uma clarificação mais densa sobre a consistência de articular os conceitos de filósofos advindos de tradições filosóficas tão distintas. Tais discussões estão em Knijnik (2012), Knijnik, Wanderer, Giongo e Duarte (2012), Knijnik e Wanderer (2013), Wanderer e Knijnik (2013).

${ }^{8} \mathrm{O}$ uso da expressão "caixa de ferramentas" está em consonância com o significado a ela atribuída por Deleuze (2002, p. 71): "Uma teoria é como uma caixa de ferramentas. Nada tem a ver com o significante... É preciso que sirva, é preciso que funcione. E não para si mesma. [...]." Desse modo, na constituição da caixa de ferramentas que conforma o que temos chamado por "Perspectiva Etnomatemática", temos nos servido de noções advindas do pensamento de Wittgenstein e de Foucault para fazê-las funcionar, na tentativa de discutir aspectos da Educação Matemática, como será detalhado no decorrer deste artigo.
} 
movimentados segundo um conjunto de regras legitimadas no campo social que orientam (e não determinam) a linguagem (KNIJNIK, 2012).

Acompanhando as discussões feitas por Knijnik e Wanderer (2013), Wanderer (2007), Giongo (2008), Duarte (2009) e Oliveira (2011), consideramos que essa Perspectiva Etnomatemática, ao incorporar as formulações de Foucault, possibilita discutir o lugar privilegiado ocupado pela Matemática escolar no currículo e seus efeitos nos processos de subjetivação dos sujeitos escolares - estudantes e professores -, desnaturalizando os enunciados que compõem o discurso da Educação Matemática. Estudos como os de Silva (2008) e Duarte (2009) têm como foco a problematização de alguns desses enunciados.

Aqui é importante destacar o entendimento não-metafísico de Foucault (1979) sobre a noção de "verdade": ela não preexiste ao mundo, esperando ser descoberta. A "verdade" se constitui historicamente através de campos de saber e de relações de poder. É correlata à produção de discursos e indissociável do acontecimento, considerando suas especificidades de espaço e de tempo. Com essas formulações, o filósofo enfatiza o caráter indissociável da positividade do discurso para a constituição da "verdade", "entend[endo] por verdade o conjunto dos procedimentos que permitem pronunciar, a cada instante e a cada um, enunciados que serão considerados como verdadeiros" (FOUCAULT, 2003, p. 233).

As noções que Wittgenstein desenvolveu em sua obra tardia oferecem elementos para o questionamento de uma das "verdades" que circula no campo científico: a existência de uma Matemática universal, que seria aplicada em diferentes formas de vida. Pesquisas etnomatemáticas como as realizadas por Wanderer (2007) e Giongo (2008) têm contribuido para a desconstrução dessa "verdade".

Afastando-se de posições que tratam como algo exótico o conhecimento matemático do outro (em um registro wittgensteiniano, os jogos de linguagem matemáticos de outras formas de vida que não a escolar), no intuito de apresentar elementos empíricos indicadores de que esses outros também raciocinam, interessa à Perspectiva Etnomatemática acima enunciada exibir e analisar jogos de linguagem matemáticos que ganham existência nas diferentes formas de vida (assim como são elementos que a constituem), entre as quais se encontram as escolares. Como indicado na literatura referente à Educação Matemática (por exemplo, nos estudos de Carraher e Schliman (2003)), os jogos matemáticos escolares não são necessariamente iguais àqueles praticados em formas de vida não-escolares. Sabemos, também, que isso produz efeitos nos 
processos educativos, na condução da conduta dos sujeitos escolares. Essas afirmações são tomadas, neste estudo, como ponto de partida: o que ainda está por ser feito é a produção de mais exemplos que sustentem tais afirmações, de modo a dar-lhes maior substância. Este artigo tem a intenção de contribuir nessa direção.

Até este ponto, oferecemos uma visão geral da Perspectiva Etnomatemática, buscando mostrar seus usos para pensar coisas de interesse para a Educação Matemática. No entanto, isso não é suficiente. Para dar consistência a este estudo, impõe-se que se discorra (mesmo que de modo breve) sobre elementos das formulações teóricas wittgensteinianas e foucaultianas que embasam a discussão empreendida sobre o material de pesquisa. Optamos por não apresentá-los em uma única seção: nesta, alguns desses elementos são mencionados; outros (especialmente os vinculados ao pensamento foucaultiano) são apresentados na seção em que empreendemos o exercício analítico.

Iniciemos por indicar que a concepção de linguagem para Wittgenstein está relacionada ao uso que é feito da palavra em determinada situação e contexto (CONDÉ, 1998). "Pode-se para uma grande classe de casos de utilização da palavra 'significação' - se não para todos os casos de sua utilização -, explicá-la assim: a significação de uma palavra é seu uso na linguagem" (WITTGENSTEIN, 1999, §43, p. 43, grifos do autor). Assim, o significado de uma palavra encontra valor de sentido em seu uso, na prática linguística, que é, em uma perspectiva wittgensteiniana, uma prática social.

Em Investigações Filosóficas, Wittgenstein traz a linguagem a seu uso cotidiano, no qual, para ele, as palavras e frases ganharão significação e passa a utilizar o termo jogos de linguagem para tratar do aspecto pragmático da linguagem, ou seja, do seu uso em contextos variados (CONDÉ, 1998). No aforisma, §23, Wittgenstein (1999) esclarece que “o termo 'jogo de linguagem' deve aqui salientar que o falar da linguagem é uma parte de uma atividade ou de uma forma de vida". Podemos dizer que é no contexto de uma determinada forma de vida que os jogos de linguagem ganham seu valor, ou seja, a significação é dada pelo uso na prática. E mais, assim como existem inúmeros jogos de linguagem, o mesmo ocorre com as variadas formas de vida. Como transitamos por diferentes formas de vida, em cada uma das formas de vida praticamos jogos de linguagem que darão sentido às expressões. Portanto, a significação não é arbitrária.

Em síntese, a articulação teórica estabelecida entre Wittgtenstein e Foucault tem sido produtiva para o desenvolvimento dos estudos etnomatemáticos desenvolvidos pelo GIPEMS - 
Grupo Interinstitucional de Pesquisa em Educação Matemática e Sociedade. Isso porque as formulações foucaultianas possibilita que sejam problematizadas "verdades" que instituem e são instituidoras do discurso da Educação Matemática, examinando "como se produzem efeitos de verdade no interior de discursos que não são em si nem verdadeiros nem falsos" (FOUCAULT, 1979, p. 7). Quanto às noções wittgensteinianas, apresentadas no período tardio de sua produção, elas se constituem em ferramentas teóricas que permitem por em questão a existência de uma única matemática, essa que tem sido nomeada por "a" matemática, assim como justificar o uso da expressão “jogos de linguagem matemáticos”. Argumenta-se sobre a possibilidade de que coexistam diferentes matemáticas, produzidas em distintas formas de vida, sendo que os jogos de linguagem que as constituiriam teriam especificidades, mas também semelhanças de família. É precisamente essa semelhança que nos permite adjetivar tais jogos por jogos de linguagem matemáticos, uma vez que se parecem com aqueles que circulam na forma de vida escolar.

\section{0 material de pesquisa e os procedimentos metodológicos}

O material de pesquisa analisado neste estudo é constituído por entrevistas (gravadas e posteriormente transcritas), realizadas no período de setembro a dezembro de 2011. A escola de Morro dos Bois possuía, na ocasião, uma singularidade se comparada às outras escolas da rede municipal de Novo Hamburgo: era a única em que todos os treze alunos, do $1^{\circ}$ ao $5^{\circ}$ ano do Ensino Fundamental, estudavam na mesma classe multisseriada.

As entrevistas ocorreram em duas etapas ${ }^{9}$. Na primeira delas foram realizadas entrevistas com sete, das doze famílias vinculadas à classe multisseriada ${ }^{10}$. Na segunda, foram selecionadas duas famílias para aprofundamento das questões relacionadas aos deveres de casa de Matemática. Para tanto, realizaram-se novas entrevistas com cada uma das mães, tendo como foco a Matemática escolar e o dever de casa. Além disso, para compor o material analítico e complementar discussões sobre a relação família-escola e sobre a participação da família na instituição escolar, no que diz respeito à Matemática escolar, especificamente no papel

\footnotetext{
${ }^{9}$ Atendendo às questões éticas envolvidas na realização de uma pesquisa, as participantes, após serem informadas sobre os objetivos do estudo e o uso que se faria das entrevistas, assinaram um Termo de Consentimento Livre e Esclarecido.

${ }^{10}$ É importante observar que mesmo gênero não sendo uma das categorias privilegiadas neste estudo, em todas as famílias houve a decisão de que seriam as mães as pessoas entrevistadas. Essa constatação converge com o discutido por autores como Chechia e Andrade (2002, 2005).
} 
desempenhado pelo grupo familiar junto à realização/verificação dos deveres de casa, também a professora foi entrevistada. As entrevistas ocorreram em seus domicílios. Essa escolha favoreceu a geração do material de pesquisa, convergindo com as discussões de Duarte (2002) sobre a mesma.

Em sintonia com o referencial teórico do estudo, as entrevistas foram consideradas como narrativas imbricadas em relações de poder-saber, em que a instauração de um saber e o exercício do poder são constituídos historicamente, na prática social. Assim, assume-se que as enunciações estão inseridas em certo regime de verdade. "Isso significa que tais enunciados nem sempre convergem ou divergem, mas que um contém o outro, estabelecendo relação sobre uma mesma base enunciativa" (ANDRADE, 2012, p. 177).

A discussão do material de pesquisa, orientada pelo referencial teórico do estudo e seu objetivo, foi realizada com base na perspectiva de análise do discurso como concebida por Foucault (1995). Isso implicou em se tomar o que foi expresso pelos participantes do estudo como situado dentro de determinados campos discursivos e ficar no nível do dito. Nesse enfoque, não há espaço para interpretações acerca das enunciações dos entrevistados ou procura por um significado oculto. Trata-se de uma análise de superfície, que não está interessada em "neutralizar o discurso, transformá-lo em signo de outra coisa e atravessar-lhe a espessura para encontrar o que permanece silenciosamente aquém dele [...]" (ibidem, p. 54). A próxima seção apresenta os resultados do exercício analítico empreendido, com base na Perspectiva Etnomatemática.

\section{Análise do material de pesquisa}

O exercício analítico levado a efeito sobre o material de pesquisa possibilitou discutir, em diferentes ângulos, a relação da escola municipal do Morro dos Bois e as famílias de seus alunos mediante a prática curricular do dever de casa de Matemática. A professora que ali lecionava o considerava como uma estratégia pedagógica para a aprendizagem de Matemática, que era proposta "todas as semanas". Consistia em "umas cinco continhas ou umas três histórias matemáticas para os maiores e para os menores uma folhinha com atividades sobre os números e contagem", que eram corrigidos em aula, após ela "conf[erir] os cadernos para ver se eles fizeram mesmo". Concebia-o como "uma forma de os alunos estudarem em casa”. Na área da 
Matemática, esse estudo ganhava relevância, pois “em Matemática a repetição é importante para o aprendizado”. (Entrevista, Professora).

As observações realizadas em sala de aula evidenciaram que também ali a repetição tanto de conteúdos, como de sequência de atividades - ocorria. Tratava-se de uma repetição implicada em um disciplinamento curricular, um controle do que se passava em sala de aula, o que nos remete às discussões foucaultianas sobre a sociedade disciplinar instituída com a Modernidade. Nas ocasiões em que o trabalho pedagógico era organizado "por ano de escolaridade", a professora demarcava a distribuição espacial dos alunos, de modo a capitalizar o tempo e o controle da atividade (MORAES; VEIGA-NETO, 2008): “As vezes eu peço pra que eles sentem em grupos por ano [escolar], $1^{o}$ e $2^{o}$ ano juntos, todos do $3^{\circ}$, todos do $4^{o}$ e do $5^{o}$, porque ai eu consigo ver o ritmo da turma e o que cada um sabe dentro do seu nível de conhecimento”. (Entrevista, Professora)

Essa organização dos alunos em sala de aula na escola de Morro dos Bois remete às discussões feitas por Foucault (2004), ao examinar como, no século XVIII, a ordenação por fileiras passou a definir a distribuição dos indivíduos no espaço escolar como uma forma de garantir o controle disciplinar dos mestres sobre seus alunos. O filósofo (ibidem) argumentou que a disciplina fabrica corpos dóceis através de três técnicas: a arte das distribuições, o controle da atividade e a organização das gêneses. A primeira delas estaria relacionada à organização dos indivíduos no espaço, e, para isso, o poder disciplinar pode se utilizar, ou não, de cercas, de muros ou de prédios fechados para o enclausuramento dos indivíduos. A disciplina teria a necessidade de dividir um espaço para cada indivíduo, evitando, assim, a formação de grupos ou de aglomeramentos. A segunda técnica remeteria ao controle rigoroso do tempo empregado nas mais diversas atividades, durante as quais o corpo deve estar totalmente aplicado à execução de sua tarefa. Já a terceira técnica se articularia com a segunda, pois o poder disciplinar sobre o tempo garantiria a organização e o controle máximo de todo o processo, para que seja alcançado o melhor resultado final do que foi produzido ou aprendido no desenvolvimento das atividades.

Assim como ocorria com os operários nas fábricas, na escola de Morro dos Bois havia ocasiões em que cada aluno possuía um lugar específico e fixo na classe. Os alunos eram distribuídos conforme orientação da professora e não tinham a permissão de trocar de lugar. Tal mecanismo de poder, "que permite o controle minucioso das operações do corpo" (ibidem, p. 118), procurava controlar não somente o que o aluno fazia/produzia, mas também a forma como 
o fazia/produzia e o tempo que levava para concluir uma tarefa. Seguindo o filósofo, podemos pensar que, naquela classe, essa técnica disciplinar "tornou possível o controle de cada um e o trabalho simultâneo de todos" (ibidem, p. 126).

No entanto, quando a atividade pedagógica envolvia o conjunto dos alunos, se instalava um afrouxamento desse disciplinamento. Ao longo do trabalho de campo, constatou-se que, nessas ocasiões, as crianças podiam livremente escolher a distribuição espacial que desejassem, sem a interferência explícita da professora, mesmo que, com isso, segundo ela, " $n \tilde{a} o$ [fosse] saber o que eles sabem" (Entrevista, Professora). Com isso, podemos pensar que estamos diante de uma estratégia que introduz a dimensão da flexibilização no trabalho escolar.

Moraes e Veiga-Neto (2008) compreendem que as mudanças decorrentes da ênfase na disciplina para a ênfase no controle constituem o deslocamento da docilidade para a flexibilidade nos processos de subjetivação que ocorrem na escola. O poder disciplinar trata cada corpo individualmente, promovendo por meio de mecanismos de poder a docilidade dos corpos - daí a importância de cada indivíduo estar posicionado em um determinado espaço e lugar, facilitando o controle, a vigilância e a regulação das atitudes e das tarefas de cada um (FOUCAULT, 2004). Por outro lado, na sociedade de controle, a utilização estratégica do espaço não é uma característica fundamental para a manutenção das atividades escolares. O lugar ocupado pelo indivíduo na organização espacial não é mais rígido, ou seja, ele tem permissão para circular por diferentes espaços, interagindo com diferentes pessoas.

Mas havia na localidade de Morro dos Bois outros dois aspectos que compunham o argumento sobre a importância do dever de casa. A professora o entendia como "uma forma de os pais ajudarem em casa seus filhos. Saberem o que eles estão estudando”. As famílias também o consideravam como uma estratégia para vigiar o que era ensinado em sala de aula. Como expressou uma das mães, ao se referir à importância de prestar auxílio à sua filha nas tarefas de casa: "E aí eu também sei o que ela está aprendendo na escola né. Eu fico mais por dentro das coisas que a professora está ensinando”(Entrevista, Mãe 1). Em um registro foucaultiano podese significar esse acompanhamento materno do dever de casa como uma estratégia de vigilância - uma das características da sociedade disciplinar. Presente em todas as estruturas institucionais, para Foucault (2004), os dispositivos de vigilância possibilitam o estabelecimento de formas e de relações de poder capazes de promover o controle da manutenção, da normalização e das 
condutas dos indivíduos pelo olhar do outro. Estes mecanismos de vigilância geram no sujeito uma interiorização de regras e normas, produzindo a docilidade dos corpos.

O segundo aspecto que reforçava o argumento da professora sobre a relevância do dever de casa era o de que "não é só o professor, os pais também têm que estar em cima, cobrando e ajudando”. Ela mostrava-se bastante contundente quanto ao papel que deveriam ocupar:

O que não dá é os pais fazerem os exercícios pelos filhos, que aí eles não aprendem. Quando eu vejo que a letra que está no caderno não é a dos alunos eu converso com os pais e explico como eles têm que fazer para ajudar os filhos e não fazer para eles [...] Não podem fazer [o tema] para os filhos e os filhos só copiarem, eles precisam explicar como se faz, dar os passos. É uma ajuda para que os filhos possam aprender. (Entrevista, Professora)

A professora contava com essa ajuda, fazendo com que o dever de casa funcionasse como uma estratégia de compartilhar a responsabilidade pela aprendizagem dos alunos entre família e escola. Em nosso país, esse compartilhamento acaba por se configurar como uma política educacional de promoção do sucesso escolar, que se transforma "de uma política tácita informal desenvolvida por famílias e escolas (e seus agentes) em uma política formal que articula os esforços educativos destas instituições" (CARVALHO, 2004, p. 95).

Nas entrevistas realizadas com as mães o tema dever de casa de Matemática surgiu recorrentemente. Elas valorizavam essa estratégia de ensino utilizada pela professora como uma possibilidade de participação nas aprendizagens matemáticas de seus filhos mesmo que, muitas vezes, afirmassem ser difícil efetivamente prestar ajuda. Uma delas justificou sua dificuldade:

[...] faz tempo que eu estudei né, não lembro de tudo, sabe? De todas as regrinhas, de como tem que se fazer para resolver as contas. É que agora eu não uso mais papel pra fazer as contas, eu faço tudo de cabeça. Mas eu sei que o certo é mostrar pra ela como se faz no papel, que é o certo como a professora ensinou. [...] Às vezes quando eu não sei, olho no caderno e me lembro, mas esses dias ela tinha tema de divisão pra fazer, aí ficou difícil, mesmo olhando eu não lembrava como fazer. Aí falei para ela perguntar para a professora, porque senão eu ia ensinar errado. (Entrevista, Mãe 2)

A fala dessa mãe aponta para um tensionamento que foi observado em outros depoimentos. Seu processo de escolarização ocorrera "faz tempo" e, por isso, nem sempre recordava "[d]as regrinhas de como se tem que fazer para resolver as contas”. Esse esquecimento não causava transtornos em seu cotidiano, uma vez que fazia "tudo de cabeça". Reconhecia que os jogos de linguagem matemáticos que praticava se diferenciam dos escolares, que "se faz[em] no papel” e que esses, ensinados pela professora, seriam os corretos. Em se 
tratando de conteúdos mais complexos, como a divisão, considerava que de pouco adiantaria buscar identificar no caderno do filho as regras aprendidas na escola, que há muito não mais seguia. Posicionada como sujeito-mãe, impelida a ser corresponsável pelo sucesso escolar de seu filho, havia a interdição de ensinar errado.

Mas as entrevistas realizadas mostraram que não só as mães daquela escola praticavam jogos de linguagem matemáticos orais, que outros estudos já mostraram estarem presentes nas formas de vida camponesa (WANDERER, 2007). Também seus filhos, antes ainda de ingressarem na escola, haviam aprendido (e seguiam praticando) essa matemática materna (assim como concebida por Sebastiani Ferreira (1993)). Era isso que ocorria com as crianças de duas das famílias, que desde pequenas acompanhavam as mães em algumas de suas atividades laborais.

Uma delas era agricultora e vendia a produção familiar em uma feira no município de Novo Hamburgo. Contou que suas duas filhas "gosta[va]m de ir na feirinha quando dá[va]. [...] A gente deixa elas pegarem o dinheiro e dar o troco", mas quando indagada de como as meninas faziam as contas para dar o troco, respondeu:

Olha, não sei. Elas fazem de cabeça, que é mais rápido que fazer no papel, mas não sei como elas pensam. Acho que é meio automático. Comigo é assim, eu nem penso muito, só faço a conta. Ninguém me ensinou como calcular de cabeça, então elas também aprenderam sozinhas. Acho que é meio natural. (Entrevista, Mãe 3)

Também a mãe que trabalhava com seu marido em uma sociedade localizada no bairro Lomba Grande, do mesmo município, lidava com dinheiro em seu trabalho e, quando possível, ou se necessário, levava consigo os filhos no final de semana, em que a família ficava "em função do trabalho na sociedade”, “cuida[ndo] da parte da venda de entradas para os eventos”, "calcula[ndo] os lucros e perdas". Isso implicava em "estar sempre lidando com as contas". Segundo ela, “às vezes não tem com quem deixar as crianças, aí a gente leva eles junto. [...] Ela [a filha que estudava na escola multisseriada] fica quase sempre na entrada vendendo entrada para o baile, ou, se tem bingo, pras fichas". Nessas ocasiões, a menina tinha que "fazer conta, porque o tempo todo tem que dar troco para as pessoas". Explicou que "na escola tem que fazer com papel e lápis, que nem a professora mostra. Mas lá na sociedade não dá. Ela faz de cabeça. Às vezes usa calculadora, mas quase sempre é de cabeça, porque "tem que ser rápido, porque o pessoal não gosta de demora". Estava ciente de que "na escola é diferente": "a professora dá as continhas prontas e eles só têm que calcular. A professora passa no quadro o que tem que fazer e 
como fazer as continhas ou os problemas. Na sociedade a questão é dinheiro, ela tem que fazer contas com dinheiro, não dá pra errar né”. (Entrevista, Mãe 2)

A análise das enunciações feitas pelas duas mães aponta para questões relevantes para o campo da Educação Matemática. Uma delas é a clara distinção que fica estabelecida entre a matemática da escola e as não-escolares. O lócus privilegiado de aprendizagem da primeira é a escola. As contas de cabeça, por outro lado, são aprendidas na forma de vida não-escolar. As crianças, "aprendem sozinhas", sendo uma aprendizagem "meio automática". A entrevistada considera que "ninguém" a ensinou a jogar os jogos da matemática oral e conjectura que isso é o que deve ter ocorrido com suas filhas. Assim como ela, também as crianças não sabem expressar as regras que seguem nesses jogos. Tampouco precisam "pensar muito" para praticar tais jogos: é "só fazer as contas". Essas enunciações nos remetem às formulações de Wittgenstein sobre seguir uma regra. Para o filósofo, trata-se de uma expressão verbal que indica uma realização um "hábito" (\$199), uma "práxis" (\$202) - e só possui significação se a considerarmos como uma atividade inserida na prática social. Portanto, para seguir corretamente uma regra em determinado jogo de linguagem não é necessário que se conheça ou se interprete a regra a priori, pois o uso na linguagem define se o que é falado tem sentido, se está em conformidade com a regra.

As mães expressaram claramente que percebiam a distinção entre os jogos de linguagem matemáticos dessas diferentes formas de vida: " $n$ a feira pode [fazer cálculo 'de cabeça'], na escola não. Na escola tem que escrever a conta", "assim, na escola tem que fazer com papel e lápis, que nem a professora mostra." De modo análogo ao discutido em outros estudos (WANDERER, 2007; GIONGO, 2008), as mulheres entrevistadas, ao fazerem contas de cabeça seguiam regras envolvendo a decomposição, a comutatividade, o arredondamento e a estimativa. $\mathrm{Na}$ escola, porém, as contas eram feitas somente "com papel e lápis", tendo como regras as usualmente utilizadas pela Matemática escolar. São regras regidas, sobretudo, pelo formalismo, por abstrações e pela supremacia do registro escrito (WANDERER, 2007; GIONGO, 2008). Em consonância com tais discussões, observamos que, na forma de vida escolar da classe multisseriada estudada, a gramática da disciplina de Matemática pressupunha certa supremacia da Matemática escrita em relação à oralidade, principalmente nas estratégias de ensino utilizadas com os alunos dos $3^{\circ}, 4^{\circ}$ e $5^{\circ}$ anos, o que, em certa medida, acabavam por reforçar a ideia da universalidade da Matemática ensinada na escola. 
No entanto, diferentemente do que ocorreu com a distinção feita pelas mães quanto às especificidades dos diferentes jogos de linguagem matemáticos das diferentes formas de vida (escolar e não escolar), a análise do material empírico inicialmente indicou que não havia menção explícita quanto a suas semelhanças de família. A busca dessa evidência foi infrutífera e fomos levados a pensar que houvera uma lacuna na produção do material empírico da pesquisa. Posteriormente, outro entendimento sobre essa questão foi levantado. Passamos a conjecturar que mais do que uma falta, poderia ser atribuído outro significado para a não menção às semelhanças entre os jogos: tal menção seria redundante, até mesmo desnecessária, devido à intensidade com que opera o discurso hegemônico da Educação Matemática, que assume como verdade inquestionável a existência de uma única matemática, "a" matemática que opera, que pode ser aplicada, usada em diferentes formas de vida. Assim, não haveria o que ressaltar sobre semelhanças entre os jogos de linguagem, pois todos pertenceriam à (única) Matemática que é reconhecida como tal. Tratar-se-ia, portanto, de uma tautologia ${ }^{11}$.

Em síntese, a discussão realizada nesta seção mostrou que o dever de casa (de Matemática), além de mobilizar os alunos, também mobiliza suas mães que, assujeitadas pelos discursos que circulam na sociedade (em particular o discurso educacional e os midiáticos), sentem-se impelidas a prestar-lhes ajuda, se veem na obrigação de auxiliá-los. Esse auxílio atende a um imperativo da sociedade contemporânea, na qual ao Estado interessa dividir com a família as responsabilidades da educação de suas crianças e jovens. Esse auxílio opera, também, de modo estratégico, no controle, por parte da família, daquilo que é realizado na escola. No que diz respeito especificamente ao dever de casa de Matemática, argumentou-se que esse está marcado por tensionamentos produzidos pelo uso (da escola e dos familiares) de jogos de linguagem diferentes (apesar de suas semelhanças de família).

\section{0 ofício da pesquisa educacional: reflexões sobre a conformação do objeto de estudo}

As palavras de fecho deste trabalho buscam refletir sobre suas possíveis implicações para ofício da pesquisa educacional (no âmbito da Educação Matemática), mais especificamente, no

\footnotetext{
${ }^{11} \mathrm{Um}$ aprofundamento desse aspecto do estudo poderá ser interessante para trazer algum tipo de contribuição para as discussões que têm sido empreendidas na área da Educação Matemática, demandando, como condição preliminar, o retorno ao campo empírico da pesquisa. Devido a limitações de espaço, optamos por, neste trabalho, apenas mencionar a questão.
} 
que diz respeito à conformação do objeto de estudo no qual estará centrada nossa atividade investigativa. Cientes de que não se trata de formular generalizações - o que estaria em dissonância com seu referencial teórico - parece-nos pertinente, no entanto, pensar para além da especificidade do que foi produzido empiricamente na localidade de Morro dos Bois e da análise aqui realizada.

Finalizado o estudo, escrito este texto, ficamos a nos indagar pelos caminhos em que fluem nossos pensamentos, quando esses são convocados a caminhar pelos meandros do oficio da pesquisa. Esse caminhar - situado num tempo-espaço bem preciso - está marcado pela provisoriedade. É ela que nos encoraja a pensar sobre nosso próprio pensamento e escrever sobre as indagações surgidas nessa complexa operação.

A questão central que muitas vezes formulamos a nós mesmos diz respeito à relevância de levar a efeito uma pesquisa que aborde múltiplos aspectos que compõem uma determinada forma de vida escolar (em nosso caso, a escola de Morro dos Bois), considerando a Educação Matemática ali praticada como somente uma (pequena) parte do complexo mundo da escola. ${ }^{12}$ Estaríamos capturados pela vontade de totalidade? Teríamos esquecido o que nos ensinou Nietzsche (2007) sobre o perspectivismo? Cientes das necessárias limitações de espaço impostas para um texto como este, ao examinar, sob diferentes perspectivas, nosso objeto de estudo (como aqui fizemos), não estaríamos correndo o risco de perder o foco em seu específico, a saber, a Educação Matemática?

Estamos diante de questões que envolvem a próprio modo de significar uma (qualquer) área do currículo escolar e seus estreitos vínculos com os mecanismos de poder-saber que atuam na sociedade. Se a significamos em sua contingência, se a situamos como parte inseparável das múltiplas dimensões que conformam as formas de vida escolares, se a considerarmos como inexoravelmente imbricada nos processos de subjetivação dos sujeitos escolares, atuando na

\footnotetext{
12 Essa questão tem recebido nossa atenção na medida em que o conhecimento científico tem sofrido, na contemporaneidade, um processo de radical fragmentação, com a instauração de campos de saber muito particulares. Essa especificidade se, por um lado, tem favorecido o aprofundamento desses campos de saber, por outro lado, tem sido criticada por produzir um esfacelamento do conhecimento, até mesmo no interior das diferentes áreas, com os severos prejuízos daí decorrentes. Como as demais áreas, a área dos estudos curriculares está submetida a essa lógica. Sua partição em subáreas - tais como a do currículo de Matemática, currículo de estudos sociais etc - produz um adensamento teórico-metodológico, mas, paradoxalmente, acaba por estreitar nosso entendimento do fenômeno educativo. Foge ao escopo deste artigo aprofundar uma discussão sobre essa dimensão do ofício da pesquisa que, como apontaram autores como Bourdieu (2012), tem estreitas conexões com as relações de poder que circulam no campo científico. As reflexões apresentadas nesta seção final do artigo têm o intuito de sinalizar para esta problemática.
} 
condução da conduta desses sujeitos, então somos levados a pensar que a (possível) contribuição de uma pesquisa que se restringisse a examinar somente aspectos internos de uma específica área do conhecimento (uma posição da qual, no presente estudo, buscamos nos afastar), poderia ficar minimizada. Porque, mesmo que provisoriamente, consideramos que fazer da pesquisa um oficio que destroça a rizomática conformação do processo educativo e se fixa somente em um de seus nós, acabaria por produzir resultados que seriam, muito provavelmente, também eles destroçados...

\section{Referências}

ABREU, G.; CLINE, T. Parents' representations of their children's mathematics learning in multiethnic primary schools. British Educational Research Journal, Londres, v. 31, n. 6, p. 697-722, dez. 2005.

AGUIAR, G. S.; ORTIGÃO, M. I. R. Letramento em Matemática: um estudo a partir dos dados do PISA 2003. Bolema, Rio Claro, v. 26, n. 42A, p. 1-21, abr. 2012.

ANDRADE, S. S. A entrevista narrativa ressignificada nas pesquisas educacionais pós-estruturalistas. In: MEYER, D. E.; PARAÍSO, M. A. (Org.). Metodologias de Pesquisas Pós-críticas em Educação. 1. ed. Belo Horizonte: Mazza Edições, 2012. p. 173-194.

BOURDIEU, P. O poder simbólico. 16. ed. Rio de Janeiro: Bertrand Brasil, 2012.

BRASIL. Projeto de Lei. Aprova o Plano Nacional de Educação para o decênio 2011-2020, e dá outras providências. 2010.

BRASIL, Lei $\mathbf{n}^{\mathbf{0}}$ 11.274, de 6 de fevereiro de 2006. Altera a redação dos arts. 29, 30, 32 e 87 da Lei no 9.394, de 20 de dezembro de 1996.

BRASIL, Lei $\mathbf{n}^{0}$ 9.394, de 20 de dezembro de 1996. Estabelece as diretrizes e bases da educação nacional. 1996.

BRASIL, Lei no 8.069, de 13 de julho de 1990. Dispõe sobre o Estatuto da Criança e do Adolescente e dá outras providências. 1990.

BREDEMEIER, M. L. L. O português como segunda língua nas escolas da imigração alemã: um estudo do Jornal da Associação de Professores Teuto-Brasileiros Católicos do Rio Grande do Sul (1900 1939). 2010. 242 f. Tese (Doutorado em Educação) - Programa de Pós-Graduação em Educação, Universidade do Vale do Rio dos Sinos, São Leopoldo, 2010.

CARRAHER, T. N.; SCHLIEMANN, A.; CARRAHER, D. W. Na vida dez, na escola zero. 13. ed. São Paulo: Cortez, 2003.

CARVALHO, M. E. P. O dever de casa como política educacional e objecto de pesquisa. Revista Lusófona de Educação, Lisboa, v. 8, n. 8, p. 85-102, jan. 2006. 
CARVALHO, M. E. P. Escola como extensão da família ou família como extensão da escola? O dever de casa e as relações família-escola. Revista Brasileira de Educação, Rio de Janeiro, v. 1, n. 25, p. 94-104, jan./abr. 2004.

CARVALHO, M. E. P. Relações entre família e escola e suas implicações de gênero. Cadernos de Pesquisa, São Paulo, v. 1, n. 110, p. 143-155, jul. 2000.

CHECHIA, V. A.; ANDRADE, A. S. O desempenho escolar dos filhos na percepção de pais de alunos com sucesso e insucesso escolar. Estudos de Psicologia, Natal, v. 10, n. 3, p. 431-440, dez. 2005.

CHECHIA, V. A.; ANDRADE, A. S. Representação dos pais sobre o desempenho escolar dos filhos. In: SEMINÁRIO DE PESQUISA, 5., 2002, Ribeirão Preto. Anais... Ribeirão Preto: USP, 2002. p. 207-219.

CONDÉ, M. L. L. Wittgenstein: linguagem e mundo. São Paulo: Annablume, 1998.

DAL'IGNA, M. C. Família S/A: um estudo sobre a parceria família-escola. 2011. 182 f. Tese (Doutorado em Educação) - Programa de Pós-Graduação em Educação, Universidade Federal do Rio Grande do Sul, Porto Alegre, 2011.

DELEUZE, G. Os intelectuais e o poder. Conversa entre Michel Foucault e Gilles Deleuze. In: FOUCAULT, M. Microfísica do poder. Rio de Janeiro: Graal, 2002. p. 69-70.

DREHER, M. N. Breve história do ensino privado gaúcho. São Leopoldo: Oikos, 2008.

DUARTE, R. Pesquisa qualitativa: reflexões sobre o trabalho de campo. Cadernos de Pesquisa, São Paulo, v. 1, n. 115, p. 139-154, mar. 2002.

DUARTE, C. G. A “realidade" nas tramas discursivas da Educação Matemática Escolar. 2009. 198 f.Tese (Doutorado em Educação) - Programa de Pós-Graduação em Educação, Universidade do Vale do Rio dos Sinos, São Leopoldo, 2009.

FERREIRA, E. S. A "Matemática-Materna" de algumas tribos indígenas brasileiras. In: ENCONTRO LUSO BRASILEIRO DE HISTÓRIA DA MATEMÁTICA, 1., 1993, Coimbra. Anais... Coimbra: Universiade de Coimbra, 1993, p. 1-12.

FOUCAULT, M. Vigiar e punir: nascimento da prisão. 28. ed. Petrópolis: Vozes, 2004.

FOUCAULT, M. Ditos e escritos IV: Estratégia, Poder-Saber. Rio de Janeiro: Forense Universitária, 2003.

FOUCAULT, M. Arqueologia do saber. 4. ed. Rio de Janeiro: Forense Universitária, 1995.

FOUCAULT, M. Microfísica do poder. Rio de Janeiro: Graal, 1979.

GIONGO, I. M. Educação Matemática e disciplinamento de corpos e saberes: um estudo sobre a Escola Estadual Técnica Agrícola Guaporé. 2008. 206 f. Tese (Doutorado em Educação) - Programa de Pós-Graduação, Universidade do Vale do Rio dos Sinos, São Leopoldo, 2008. 
GLORIA, D. M. A. Relação entre escolaridade e diferenças constitutivas das fratrias. Paidéia, Ribeirão Preto, v. 15, n. 30, p. 31-42, abr. 2005.

KNIJNIK, G. Differentially positioned language games: ethnomathematics from a philosophical perspective. Educational Studies in Mathematics, Nova Iorque, v. 80, n. 1-2, p. 87-100, mar. 2012.

KNIJNIK, G.; WANDERER, F. Programa Escola Ativa, escolas multisseriadas do campo e educação matemática. Educação e Pesquisa, São Paulo, v. 39, n. 1, p. 211-225, jan./mar. 2013.

KNIJNIK, G. "A vida deles é uma matemática”: regimes de verdade sobre a educação matemática de adultos do campo. Educação Unisinos, São Leopoldo, v. 10, n. 1, p. 56-61, jan./abr. 2006.

KNIJNIK, G.; WANDERER, F.; GIONGO, I.M.; DUARTE, C. G. . Etnomatemática em movimento. Belo Horizonte: Autêntica Editora, 2012.

KREUTZ, L. Escolas comunitárias de imigrantes no Brasil: instâncias de coordenação e estruturas de apoio. Revista Brasileira de Educação, Rio de Janeiro, v. 1, n. 15, p. 159-177, set./dez. 2001.

MCMULLEN, R.; ABREU, G. Parents' experiences as mediators of their children's learning: the impact of being a parent-teacher. Cerme 6, Lyon, France, v. 1, n. 1, p. 54-64, jan. 2009.

MORAES, A. L.; VEIGA-NETO, A. Disciplina e controle na escola: do aluno dócil ao aluno flexível. In: COLÓQUIO LUSO-BRASILEIRO SOBRE QUESTÕES CURRICULARES, 4., 2008. Florianópolis. Anais... Florianópolis: UFSC, 2008. p. 1-18.

MOREIRA, P. C. $3+1$ e suas (In)Variantes (Reflexões sobre as possibilidades de uma nova estrutura curricular na Licenciatura em Matemática). Bolema, Rio Claro, v. 26, n. 44, p. 1137-1150, dez. 2012.

NIETZSCHE, F. Além do bem e do mal: prelúdio a uma filosofia do futuro. São Paulo: Companhia de Bolso, 2007.

OLIVEIRA, C. B. E.; MARINHO-ARAUJO, C. M. A relação família-escola: intersecções e desafios. Estudos de Psicologia, Campinas, v. 7, n. 1, p. 99-108, jan./mar. 2010.

OLIVEIRA, S. S. Matemáticas de formas de vida de agricultores do município de Santo Antônio da Patrulha. 2011. 114 f. Dissertação (Mestrado em Educação) - Programa de Pós- Graduação em Educação, Universidade do Vale do Rio dos Sinos, São Leopoldo, 2011.

REALI, A. M. M. R.; TANCREDI, R. M. S. P. A importância do que se aprende na escola: a parceria escola-família em perspectiva. Paidéia, Ribeirão Preto, v. 15, n. 31, p. 239-247, ago. 2005.

SILVA, F. B. S. A(prender) matemática é difícil: problematizando verdades do currículo escolar. 2008. 118 f. Dissertação (Mestrado em Educação) - Programa de Pós-Graduação em Educação, Universidade do Vale do Rio dos Sinos, São Leopoldo, 2008.

SILVA, M. A.; PIRES, C. M. C. Organização curricular da matemática no Ensino Médio: a recursão como critério. Ciência \& Educação, Bauru, v. 19, n. 2, p. 249-266, jan. 2013.

WANDERER, F. Escola e matemática escolar: mecanismos de regulação sobre sujeitos escolares de uma localidade rural de colonização alemã do Rio Grande do Sul. 2007. 228 f. Tese (Doutorado em 
Educação) - Programa de Pós-Graduação em Educação, Universidade do Vale do Rio dos Sinos, São Leopoldo, 2007.

WANDERER, F.; KNIJNIK, G. O discurso da avaliação do Programa Escola Ativa no âmbito da educação (matemática). In: CONGRESSO INTERNACIONAL DE AVALIAÇÃO - VIII CONGRESSO INTERNACIONAL DE EDUCAÇÃO, 3., 2013, Gramado. Anais... São Leopoldo: Casa Leria, 2013, p. 113.

WITTGENSTEIN, L. Investigações Filosóficas. Trad. J. C. Bruni. São Paulo: Nova Cultural, 1999. (Coleção Os Pensadores).

Submetido em Agosto de 2013. Aprovado em Janeiro de 2014. 